\title{
Desempenho e Características de Carcaça de Bezerros Confinados Recebendo Dietas com Diferentes Degradabilidades da Fração Protéica ${ }^{1}$
}

\section{Rafael da Costa Cervieri ${ }^{2}$, Mário De Beni Arrigoni $^{3}$, Henrique Nunes de Oliveira ${ }^{4}$, Antônio Carlos Silveira ${ }^{5}$, Luis Arthur Loyola Chardulo ${ }^{6}$, Ciniro Costa ${ }^{7}$, Cyntia Ludovico Martins ${ }^{8}$}

\begin{abstract}
RESUMO - O objetivo deste trabalho foi avaliar as respostas do fornecimento de dietas com diferentes níveis de proteína degradável no rúmen (PDR), durante a fase inicial de confinamento, no desempenho, nas características de crescimento monitoradas in vivo por ultrasonografia e nos parâmetros de carcaça e qualidade de carne de bovinos jovens. Foram utilizados 60 bezerros Brangus não castrados, com 8 meses e peso vivo médio de $243,2 \mathrm{~kg}$, submetidos a três tratamentos nas fases de crescimento (Fase 1) e terminação (Fase 2): T1 - 69\% PDR nas Fases 1 e 2; T2 - 77\% PDR na Fase 1 e 69\% PDR na Fase 2; T3 - 61\% PDR na Fase 1 e 69\% PDR na Fase 2. Na Fase 1, os animais do tratamento T2 apresentaram menor ganho de peso médio diário que os animais do tratamento T1 e pior conversão alimentar que T1 e T3. O peso de carcaça quente, seu rendimento e os pesos de dianteiro, ponta de agulha e traseiro, bem como a área de olho de lombo, gordura subcutânea, força de cisalhamento e composição química da carne, não apresentaram diferença estatística entre tratamentos. A utilização de dietas com menor teor de PDR melhorou a conversão alimentar e o ganho de peso médio diário em até 11,5 e 16,9\%, respectivamente, na fase de crescimento, indicando a utilização de menores níveis de PDR neste período.
\end{abstract}

Palavras-chave: Brangus, carcaça, proteína degradável no rúmen, superprecoce

\section{Performance and Carcass Traits of Feedlot Calves Receiving Diets with Different Degradabilities of the Protein Fraction}

\begin{abstract}
The objective of this study was to evaluate the effects of different levels of degradable intake protein (DIP) diets during the feedlot-growing phase, on performance, in vivo growth parameters measured by ultrasound and on carcass traits and meat quality of young bulls. Sixty Brangus calves, 8 months old, averaging 243,2 kg, were submitted to three treatments in growing (Phase 1) and finishing (Phase 2) phases: T1 - 69\% DIP in Phases 1 and 2; T2 - 77\% DIP in Phase 1 and 69\% DIP in Phase 2; T3 - 61\% DIP in Phase 1 and 69\% DIP in Phase 2. In Phase 1, animals on treatments T2 showed a lower average daily gain than those on treatments $\mathrm{T} 1$ and worst feed conversion than $\mathrm{T} 1$ and $\mathrm{T} 3(\mathrm{P}<.05)$. Hot carcass weight, dressing percentage, weights of the forequarter, plate and hindquarter, and the rib eye area, fat thickness, shear force and chemical composition did not statistically differ among treatments. Diets with less DIP improved feed conversion and average daily gain in 11.5 and $16.9 \%$, respectively, during the growing phase, suggesting the use of lower levels of DIP during this period.
\end{abstract}

Key Words: Brangus, carcass, degradable intake protein, young bulls

\section{Introdução}

As exigências protéicas dos ruminantes são atendidas pelos aminoácidos absorvidos no intestino delgado, sendo estes provenientes da proteína microbiana e da proteína dietética não degradada no rúmen (VALADARES FILHO, 1995), definindo assim o conceito de proteína metabolizável.

A quantidade de aminoácidos disponíveis para a absorção deve ser igual às necessidades de aminoácidos para atender os requerimentos de mantença e produção dos ruminantes. Contudo, quando o objetivo é atingir elevados níveis de produção, ocorre aumento nas exigências protéicas e, para atender esta condição, há necessidade de maximizar a eficiência de síntese de proteína microbiana, contanto que parte da proteína dietética ingerida não seja degradada no rúmen (Broderick et al., 1991, citados por VALADARES FILHO, 1995).

\footnotetext{
${ }_{1}^{1}$ Parte da Dissertação apresentada pelo primeiro autor à FMVZ, UNESP, Botucatu, SP.

2 Zootecnista, Aluno de Mestrado do curso de Pós-Graduação em Zootecnia, FMVZ, UNESP. Cx. Postal 560, CEP 18610-000, Botucatu-SP Bolsista da FAPESP. E.mail: cervieri@bigfoot.com

3 Zootecnista, Prof. Ass., Dep. Melhor. e Nutr. Animal, FMVZ, UNESP.

${ }_{5}^{4}$ Médico Veterinário, Prof. Ass., Dep. Melhor. e Nutr. Animal, FMVZ, UNESP

${ }^{5}$ Engenheiro-Agrônomo, Prof. Titular, Dep. Melhor. e Nutr. Animal, FMVZ, UNESP.

${ }^{6}$ Zootecnista, Prof. Ass, Dep. Química, IB, UNESP.

${ }^{7}$ Zootecnista, Prof. Ass., Dep. Melhor. e Nutr. Animal, FMVZ, UNESP.

${ }^{8}$ Médica Veterinária, Aluna de Doutorado do Curso de Pós-Graduação em Zootecnia, FMVZ, UNESP.
} 
O modelo biológico Superprecoce caracteriza-se pela utilização de animais jovens e com altas taxas de crescimento, que possuem grande demanda de proteína tanto qualitativa como quantitativamente, principalmente na fase inicial do crescimento pós-desmame. As informações a respeito das proporções de proteína degradável no rúmen (PDR) e de proteína não degradável no rúmen (PNDR) que devem ser fornecidas nas dietas são escassas, pois é sempre dada ênfase aos teores de proteína bruta utilizados nas formulações, existindo, portanto, a necessidade de uma caracterização mais adequada da fração protéica dentro deste sistema intensivo de produção.

Segundo LUCHIARI FILHO (1998), a utilização de bovinos jovens e não castrados é uma alternativa viável para a produção de carne, dada a atual demanda de mercado por um produto mais magro e saudável. Entretanto, faz-se necessário o uso de raças ou cruzamentos e manejo alimentar que possibilitem nível mínimo de gordura de cobertura, para que o resfriamento e o processamento da carne se tornem adequados, além de assegurar ao consumidor um produto saboroso.

Os efeitos dos sistemas de alimentação e dos níveis nutricionais nas características das carcaças bovinas são fartamente documentados, principalmente no que se refere ao nível energético (FELÍCIO, 1997). Quanto à utilização de fontes ou níveis protéicos, os resultados observados têm sido discretos ou mesmo ausentes (SINDT et al., 1993; SHAIN et al., 1998; McCOY et al., 1998).

O objetivo deste trabalho foi comparar o ganho de peso médio diário, conversão alimentar, consumo de matéria seca, características de crescimento monitoradas in vivo por ultra-sonografia, parâmetros de carcaça, qualidade e composição química da carne de bovinos da raça Brangus, não castrados e confinados pós-desmama, submetidos a dietas com diferentes degradabilidades ruminais da fração protéica na fase inicial de confinamento, com base nas exigências desta fração propostas pelo NATIONAL RESEARCH COUNCIL - NRC (1996).

\section{Material e Métodos}

O estudo foi realizado no período de Junho a Dezembro de 1998. Foram utilizados 60 bovinos da raça Brangus (3/8 Nelore e 5/8 Aberdeen Angus), não castrados, desmamados aos sete meses de idade, com peso vivo médio de $214,2 \pm 20,5 \mathrm{~kg}$, criados em sistema de pastejo rotacionado de Brachiaria brizantha e suplementados com concentrado no sistema "creep-feeding". Após a desmama, os bezerros foram identificados, distribuídos nos tratamentos e submetidos a controle sanitário (contra endo e ectoparasitos, policlostridiose), sendo encaminhados para as baias de confinamento onde permaneceram por 178 dias, sendo 28 dias para adaptação às dietas e ao manejo, 92 dias para a Fase 1 (crescimento) e 58 dias para a Fase 2 (terminação).

Os animais foram submetidos a três tratamentos, correspondentes às dietas, que possuíam diferentes teores de PDR em relação à proteína bruta, considerando-se duas fases: T1 - 69 \% PDR nas Fases 1 e 2; T2 - 77\% PDR na Fase 1 e 69\% PDR na Fase 2; e T3 - 61\% PDR na Fase 1 e 69\% PDR na Fase 2.

Durante o período experimental foram realizadas pesagens a cada 28 dias, para monitoração do ganho de peso médio diário e ajustes nas dietas, sempre antes da primeira refeição do dia (07:00) e com jejum alimentar prévio de 16 horas. O peso vivo inicial do período experimental foi obtido após a fase de adaptação.

O confinamento possuía cochos cobertos (com 0,80 m lineares/cabeça), bebedouros do tipo Australiano e foi subdividido com cerca elétrica em 12 baias coletivas, sendo quatro por tratamento.

O consumo de matéria seca foi mensurado dentro de cada tratamento, subdividido em 4 baias com 5 animais cada, por meio da pesagem do alimento fornecido diariamente, fazendo-se posteriormente a média de consumo por animal. As sobras de alimento foram pesadas a cada quatro dias.

Para estabelecimento das exigências e formulação das dietas, utilizou-se o programa do NRC (1996) nível 2, que se baseia em simulação ruminal, para animais não castrados em crescimento, com níveis de ganhos de peso diários de $1,20 \mathrm{~kg} /$ dia na Fase 1 e de $1,50 \mathrm{~kg} /$ dia na Fase 2. Para os ingredientes das dietas, foram utilizados os valores de PDR e PNDR do próprio NRC (1996).

$\mathrm{O}$ alimento foi fornecido ad libitum, duas vezes ao dia, em sistema de ração completa. Utilizou-se a silagem de milho e alimentos concentrados formulados para cada tratamento (Tabela 1). Todas as dietas continham ionóforo(Rumensin ${ }^{\circledR}, 300 \mathrm{mg} /$ cabeça/dia) e eram isoenergéticas e isoprotéicas, nas duas fases.

A monitoração in vivo do crescimento dos animais foi feita segundo metodologia proposta por PERKINS et al. (1992), utilizando-se unidade de 
Tabela 1 - Composição e características nutricionais das dietas (em relação à MS total)

Table 1 - Composition and nutritional aspects of the diets (DM basis)

\begin{tabular}{|c|c|c|c|c|}
\hline \multirow[b]{2}{*}{ Item (\%) } & \multicolumn{2}{|c|}{$\begin{array}{l}\text { Fase } 1 \\
\text { Phase } 1\end{array}$} & \multicolumn{2}{|c|}{$\begin{array}{l}\text { Fase } 2 \\
\text { Phase } 2\end{array}$} \\
\hline & $\begin{array}{l}\text { PDR } 69 \% \\
69 \% \text { DIP } \\
\end{array}$ & $\begin{array}{l}\text { PDR } 77 \% \\
77 \% \text { DIP }\end{array}$ & $\begin{array}{r}\text { PDR } 61 \% \\
61 \% \text { DIP } \\
\end{array}$ & $\begin{array}{r}\text { PDR } 69 \%{ }^{1} \\
69 \% \text { DIP } \\
\end{array}$ \\
\hline $\begin{array}{l}\text { Silagem de milho } \\
\text { Corn silage }\end{array}$ & 30,0 & 30,5 & 30,5 & 25,0 \\
\hline $\begin{array}{l}\text { Milho grão moído } \\
\text { Ground corn }\end{array}$ & 51,8 & 52,1 & 53,1 & 51,0 \\
\hline $\begin{array}{l}\text { Caroço de algodão } \\
\text { Cottonseed }\end{array}$ & 5,5 & 6,4 & 2,0 & 17,0 \\
\hline $\begin{array}{l}\text { Farelo de soja } \\
\text { Soybean meal }\end{array}$ & 6,3 & 5,5 & 6,4 & 2,2 \\
\hline $\begin{array}{l}\text { Amiréia } \\
\text { Amirea }\end{array}$ & 1,3 & 2,3 & 0,4 & 1,2 \\
\hline $\begin{array}{l}\text { Uréia } \\
\text { Urea }\end{array}$ & 0,9 & 1,5 & 0,5 & 0,4 \\
\hline $\begin{array}{l}\text { Farinha de sangue } \\
\text { Blood meal }\end{array}$ & 2,6 & 0,13 & 5,4 & 1,2 \\
\hline $\begin{array}{l}\text { Sal mineral }{ }^{2} \\
\text { Mineral premix }\end{array}$ & 1,6 & 1,6 & 1,7 & 1,7 \\
\hline $\begin{array}{l}\text { Rumensin } 3 \\
\mathrm{~PB}^{4} \\
C P\end{array}$ & $\begin{array}{l}0,04 \\
16,0\end{array}$ & $\begin{array}{l}0,04 \\
16,0\end{array}$ & $\begin{array}{c}0,04 \\
16,2\end{array}$ & $\begin{array}{l}0,04 \\
13,7\end{array}$ \\
\hline $\begin{array}{l}\text { PDR } \\
D I P\end{array}$ & 11,2 & 12,2 & 10,4 & 9,45 \\
\hline $\begin{array}{l}\text { NDT } \\
T D N\end{array}$ & 76,0 & 75,0 & 77,0 & 78,0 \\
\hline $\begin{array}{l}\mathrm{Elg}(\mathrm{Mcal} / \mathrm{kg})^{5} \\
\text { Neg }\end{array}$ & 1,19 & 1,16 & 1,22 & 1,23 \\
\hline $\begin{array}{l}\text { FDN } \\
N D F\end{array}$ & 26,0 & 27,0 & 26,0 & 28,0 \\
\hline $\begin{array}{l}\text { Relação volumoso:concentrado } \\
\text { Roughage:concentrateratio }\end{array}$ & $30: 70$ & $30: 70$ & $30: 70$ & $25: 75$ \\
\hline
\end{tabular}

ultra-sonografia veterinária "Pie Medical - Scanner 200", com sonda "Sector Curved Array Scanner", modelo 51B04UM02, para verificar o desenvolvimento do tecido adiposo subcutâneo, bem como a área do músculo Longissimus dorsi. Este procedimento foi efetuado duas vezes em cada animal, um mês antes do abate e no mesmo dia em os animais embarcaram para o frigorífico.

Ao término do confinamento, os animais foram abatidos, com idade média de 13 meses, com jejum alimentar prévio de 24 horas. Foram pesadas as meia-carcaças quentes (direita e esquerda), que, em seguida, foram resfriadas em câmara fria por 24 horas. O rendimento de carcaça quente foi calcula- do pela relação entre o peso da carcaça quente e o peso vivo final obtido na fazenda (após jejum alimentar de 16 horas), expresso em porcentagem. Os pesos dos quartos traseiro, dianteiro e ponta de agulha foram obtidos após o resfriamento das carcaças por 24 horas.

As meia-carcaças esquerdas serviram para a coleta das amostras do músculo Longissimus dorsi, sendo retirada uma seção entre a $12^{\mathrm{a}}$ e $13^{\mathrm{a}}$ costelas. As amostras foram identificadas, embaladas em plástico e congeladas (freezer a $-20^{\circ} \mathrm{C}$ ), para posteriores análises de camada de gordura subcutânea, área de Longissimus dorsi, força de cisalhamento ("shear force") e composição química da carne. A seção 
retirada entre a $12^{\mathrm{a}}$ e $13^{\mathrm{a}}$ costelas foi serrada, ainda congelada, em duas porções: uma porção com espessura de $1 \mathrm{~cm}$ para realização das análises químicas; outra com espessura de $2,54 \mathrm{~cm}$, correspondendo à região da $12^{\mathrm{a}}$ costela, utilizada para as medidas de gordura subcutânea, área de Longissimus dorsi e força de cisalhamento. Todas as medidas e análises realizadas foram feitas após o descongelamento das amostras, a uma temperatura de 3 a $5^{\circ} \mathrm{C}$, por 48 horas.

A espessura de gordura subcutânea e a área de Longissimus dorsi foram obtidas de acordo com metodologia descrita por MÜLLER (1987). Para a verificação da força de cisalhamento foi adotado o procedimento seguido por WHEELER et al. (1994), utilizando-se de um "Warner - Bratzler Shear Force - Chatillon" mecânico com capacidade de $25 \mathrm{~kg}$. As determinações de umidade, proteína bruta e extrato etéreo (teor de lipídeos intramuscular) seguiram os procedimentos da ASSOCIATION OF OFFICIAL ANALYTICAL CHEMISTS - AOAC (1985).

Para o desempenho e características de cresci- mento monitoradas in vivo, o delineamento experimental adotado foi inteiramente casualizado, em parcelas subdivididas, com três tratamentos correspondendo aos três tipos de ração da Fase 1 e dois períodos correspondendo às duas fases do experimento. Para os demais parâmetros, o delineamento experimental utilizado foi o inteiramente casualizado. $\mathrm{Na}$ avaliação da conversão alimentar, as baias contendo cinco animais foram consideradas as unidades experimentais. Os resultados foram analisados por intermédio do programa computacional Statistical Analysis System (SAS, 1985) e os dados foram submetidos à análise de variância, por intermédio do procedimento GLM. Para comparação entre as médias, utilizou-se o teste de Tukey a $5 \%$ de probabilidade.

\section{Resultados e Discussão}

Nas Tabelas 2 e 3 são apresentados os valores médios dos pesos vivos inicial e final, ganho de peso médio diário, consumo de matéria seca e conversão

Tabela 2 - Médias de desempenho da Fase 1 e seus respectivos desvios-padrão

Table 2 - Phase 1 performance means and its respective standard deviations

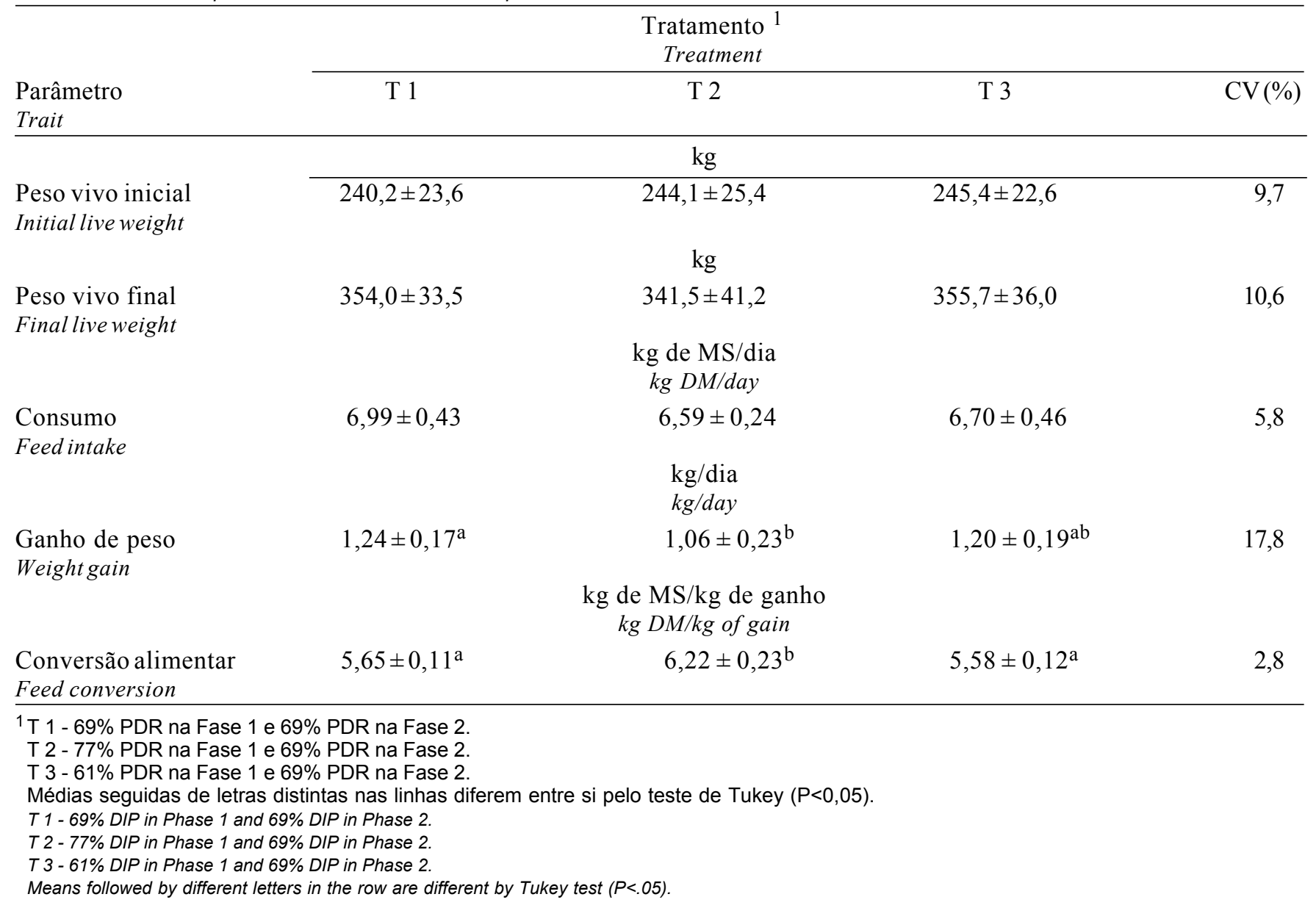


alimentar, para as Fases 1 e 2 e para o período total de confinamento. Os resultados da análise estatística mostraram a existência de interação entre fase $\mathrm{X}$ tratamento apenas para o ganho de peso médio diário e a conversão alimentar $(\mathrm{P}<0,05)$.

Não se detectou diferença $(\mathrm{P}>0,05)$ para peso vivo inicial e final e consumo de matéria seca na Fase 1 do confinamento (Tabela 2). Estes resultados estão de acordo com COOMER et al. (1993), que também não encontraram diferenças entre os consumos de matéria seca de novilhos de ano recebendo dietas com diferentes proporções de PNDR até 56 dias de confinamento. Observa-se, também na Tabela 2, que o ganho de peso médio diário diferiu entre os tratamentos $(\mathrm{P}<0,05)$, sendo que os animais do tratamento $\mathrm{T} 1$ apresentaram ganho $16,9 \%$ maior que os do tratamento T2. Quanto à conversão, os animais do tratamento T2 foram $9,7 \%$ menos eficientes que os demais $(\mathrm{P}<0,05)$. Resultados semelhantes foram obtidos por FLUHARTY et al. (1994), sendo que os bezerros castrados que receberam dietas com maior fração de PNDR foram 7,6\% mais eficientes na utilização dos alimentos e apresentaram ganho de peso $10,6 \%$ maior durante os 52 dias iniciais de experimento.

SINDT et al. (1993) observaram que bezerros castrados, oriundos de cruzamento com a raça Charolesa, alimentados em confinamento com uréia e uma mistura de farinha de sangue e farinha de penas, apresentaram maior eficiência alimentar nos primeiros 41 dias de confinamento, quando comparados aos que receberam dietas com maior teor de PDR, tendo uréia como único suplemento protéico, porém não foi observada diferença para ganho de peso. Por outro lado, COOMER et al. (1993) constataram que a suplementação de novilhos de ano com fontes de PNDR (farelo de soja aquecido e farelo de glúten de milho), durante os 56 dias iniciais de confinamento, não interferiu no ganho de peso médio diário e a eficiência alimentar dos animais.

Os valores médios observados para conversão alimentar estão próximos dos obtidos por ARRIGONI (1995) e SAMPAIO et al. (1997), que verificaram conversão média de 5,85 e 5,82 kg de MS/kg de ganho, respectivamente, para bezerros não castrados, alimentados ad libitum durante a fase inicial de confinamento.

Os melhores resultados obtidos quanto ao ganho médio de peso para os animais do tratamento $\mathrm{T} 1 \mathrm{e}$ conversão alimentar para os dos tratamentos T1 e T3 durante a Fase 1, podem ser atribuídos ao atendimento adequado da maior exigência de proteína do ganho dos animais, já que bezerros não castrados e recém desmamados apresentam maior crescimento muscular em comparação ao comportamento de deposição do tecido adiposo durante o período inicial de confinamento. Assim, a necessidade de proteína metabolizável é elevada nesta fase (Sindt et al., 1994, citados por McCOY et al., 1998) e para atender esta demanda, a proteína dietária oriunda dos ingredientes básicos ou de suplementos protéicos deve escapar da degradação ruminal e tornar-se disponível para absorção no intestino delgado (Chalupa, 1975, citado por LOERCH et al., 1983). O fornecimento de fonte de baixa degradação ruminal, como a farinha de sangue, ou das dietas com maior teor de PNDR, pode ter disponibilizado maior quantidade de proteína para absorção no intestino.

Neste sentido, as melhores respostas alcançadas mediante a suplementação com fontes ou dietas com maior teor de PNDR, apesar de não avaliados neste trabalho, têm sido atribuídas ao maior fluxo de aminoácidos de origem dietária para o duodeno (ZINN et al., 1981; TITGEMEYER et al., 1989) ou mesmo maior retenção de nitrogênio pelo organismo (Cecava e Hancock, 1994 citados por KNAUS et al., 1998).

ZINN e OWENS (1993) concluíram que a suplementação de dietas para bezerros implantados e confinados, alimentados com fontes protéicas de escape ruminal, proporcionam aumento linear na passagem de nitrogênio provindo de aminoácidos para o intestino delgado. Aumentos nos fluxos de proteína bruta, aminoácidos e aminoácidos essenciais para o abomaso bem como maior absorção no intestino foram observados por COOMER et al. (1993) ao fornecerem farelo de soja aquecido e farelo de glúten de milho a novilhos fistulados, levando os autores a concluírem que dietas suplementadas com PNDR aumentam o suprimento de proteína metabolizável para bovinos jovens.

Entretanto, PERRY e CECAVA (1995) apontam que em dietas com alta proporção de alimentos concentrados contendo elevadas proporções de milho, a suplementação com altos níveis de PNDR poderá reduzir a performance animal quando comparada à suplementação com farelo de soja. Isto ocorre devido à diminuição da concentração de nitrogênio amoniacal no rúmen, o que limitaria a síntese de proteína microbiana. Da mesma forma, LANNA et al. (1998) comentam que em dietas de alta energia à base de milho, que apresenta uma fração protéica (zeína) de baixa degradabilidade ruminal, há necessidade de uso de fontes de PDR, visando atender as exigências microbianas. Para que esta possível redução do nível de amônia ruminal não interferisse na produção de 
proteína bruta microbiana com conseqüente redução da quantidade de proteína metabolizável, todas as dietas no presente estudo, incluindo as que possuíam maior teor de farinha de sangue, foram suplementadas com fontes de alta degradação ruminal, especificamente uréia e amiréia (produto comercial resultado da extrusão de amido com uréia).

Porém, quando fornecido maior teor de PDR (T2), que propiciaria maior concentração de amônia no ambiente ruminal e evitaria possível deficiência de nitrogênio, verificaram-se resultados inferiores para este tratamento na Fase 1, quanto ao ganho de peso médio diário e conversão alimentar. Tal resposta pode estar relacionada ao não preenchimento das exigências de proteína metabolizável dos bezerros, pois a quantidade de proteína de origem microbiana mais a fração de escape dos demais alimentos não tenham sido suficientes para que fossem atingidos ganhos de peso mais elevados.

Outro aspecto a ser considerado é a quantidade de energia e seu sincronismo de degradação com a fonte protéica, estando relacionada diretamente com o processamento dos grãos. No presente estudo, utilizaram-se dietas isoenergéticas, sendo que a fonte principal de energia foi o milho moído grosso, cuja digestão tem comportamento intestinal, associado à porcentagem de milho naturalmente presente na silagem, que apresenta comportamento de maior de-

Tabela 3 - Médias de desempenho na Fase 2 e período total e seus respectivos desvios-padrão

Table 3 - Phase 2 and total performance means and its respectively standard deviations

\begin{tabular}{|c|c|c|c|c|}
\hline \multirow[b]{2}{*}{$\begin{array}{l}\text { Parâmetro } \\
\text { Trait }\end{array}$} & \multicolumn{3}{|c|}{$\begin{array}{c}\text { Tratamento } \\
\text { Treatment }\end{array}$} & \multirow[b]{2}{*}{$\mathrm{CV}(\%)$} \\
\hline & T 1 & Т 2 & T 3 & \\
\hline & & $\mathrm{kg}$ & & \\
\hline $\begin{array}{l}\text { Peso vivo final } \\
\text { Final live weight }\end{array}$ & $435,8 \pm 41,8$ & $\begin{array}{l}426,0 \pm 52,3 \\
\mathrm{~kg} \mathrm{de} \mathrm{MS/dia} \\
\text { Kg DM/day }\end{array}$ & $434,9 \pm 41,5$ & 10,5 \\
\hline $\begin{array}{l}\text { Consumo } \\
\text { Feed intake }\end{array}$ & $8,93 \pm 0,46$ & $\begin{array}{c}8,56 \pm 0,16 \\
\mathrm{~kg} / \mathrm{dia} \\
\text { Kg/day }\end{array}$ & $8,69 \pm 0,40$ & 4,2 \\
\hline $\begin{array}{l}\text { Ganho de peso } \\
\text { Weight gain }\end{array}$ & $1,41 \pm 0,26$ & $\begin{array}{c}1,46 \pm 0,30 \\
\mathrm{~kg} \mathrm{de} \mathrm{MS} / \mathrm{kg} \text { de ganho } \\
\mathrm{kg} D M / \mathrm{kg} \text { of gain }\end{array}$ & $1,37 \pm 0,21$ & 17,9 \\
\hline $\begin{array}{l}\text { Conversão alimentar } \\
\text { Feed conversion } \\
\text { Total }\end{array}$ & $6,37 \pm 0,51$ & $5,90 \pm 0,42$ & $6,39 \pm 0,61$ & 8,3 \\
\hline & & $\begin{array}{l}\mathrm{kg} \text { de } \mathrm{MS} / \mathrm{dia} \\
K g \text { DM/day }\end{array}$ & & \\
\hline $\begin{array}{l}\text { Consumo } \\
\text { Feed intake }\end{array}$ & $7,96 \pm 1,12^{b}$ & $\begin{array}{c}7,57 \pm 1,07^{\mathrm{a}} \\
\mathrm{kg} / \mathrm{dia} \\
\mathrm{Kg} / \text { day }\end{array}$ & $7,69 \pm 1,13^{b}$ & 1,7 \\
\hline $\begin{array}{l}\text { Ganho de peso } \\
\text { Weight gain }\end{array}$ & $1,30 \pm 0,16$ & $\begin{array}{c}1,21 \pm 0,20 \\
\mathrm{~kg} \mathrm{de} \mathrm{MS} / \mathrm{kg} \text { de ganho } \\
\mathrm{kg} D M / \mathrm{kg} \text { of gain }\end{array}$ & $1,26 \pm 0,16$ & 15,2 \\
\hline $\begin{array}{l}\text { Conversão alimentar } \\
\text { Feed conversion }\end{array}$ & $6,01 \pm 0,51$ & $6,06 \pm 0,36$ & $5,98 \pm 0,59$ & 6,5 \\
\hline
\end{tabular}

1 T 1 - 69\% PDR na Fase 1 e 69\% PDR na Fase 2.

T 2 - 77\% PDR na Fase 1 e 69\% PDR na Fase 2.

T 3 - 61\% PDR na Fase 1 e $69 \%$ PDR na Fase 2.

$T 1-69 \%$ DIP in Phase 1 and 69\% DIP in Phase 2.

T $2-77 \%$ DIP in Phase 1 and 69\% DIP in Phase 2.

T $3-61 \%$ DIP in Phase 1 and 69\% DIP in Phase 2.

Rev. bras. zootec., 30(5):1590-1599, 2001 
gradação ruminal (OWENS et al., 1986). Devido ao baixo teor de grãos presentes na silagem de milho fornecida, identificado pelos baixos teores de matéria seca, pode-se inferir que não houve disponibilidade suficiente de amido para otimização da síntese microbiana, que desencadearia maior aporte de aminoácidos para o intestino.

Quanto à Fase 2 (Tabela 3), tanto o peso vivo final e o ganho de peso médio diário, como o consumo de matéria seca e a conversão alimentar não diferiram $(\mathrm{P}>0,05)$ entre tratamentos. Da mesma forma, SINDT et al. (1993) constataram que, a partir de 79 dias de confinamento, bezerros cruzados e não castrados arraçoados com dietas contendo uréia ou uréia mais farinha de sangue e penas não apresentaram diferença para consumo de matéria seca, ganho de peso e eficiência alimentar.

A média de ganho de peso observada nesta fase $(1,41 \mathrm{~kg} /$ cabeça/dia) foi mais elevada que a obtida por SAMPAIO et al. (1997), que também trabalharam com bezerros pós-desmama não castrados, alimentados com três fontes protéicas, sendo que estes apresentaram ganho médio da ordem de $1,20 \mathrm{~kg} / \mathrm{cabeça} /$ dia.

Para o período total de confinamento (Tabela 3), verifica-se a existência de diferença significativa $(\mathrm{P}<0,05)$ somente para o consumo de matéria seca, sendo este mais elevado para os animais do tratamento T1. Estes resultados estão de acordo com MILTON et al. (1997) que não encontraram diferenças no ganho de peso médio diário e eficiência alimentar em novilhos de ano castrados, recebendo apenas uréia ou uréia mais farinha de sangue e glúten de milho. Por outro lado, ZINN e OWENS (1993), ao compararem o desempenho de bezerros implantados submetidos a dietas tendo apenas uréia ou uréia mais 2,4 ou $6 \%$ de uma mistura de fontes de PNDR como suplementos protéicos, durante o período de confinamento, observaram que os animais que receberam a suplementação adicional de $2 \%$ apresentaram taxa e eficiência de ganho 13,4 e 8,4\% maiores respectivamente.

Quanto à importância do nível de PDR na fase final do confinamento, observa-se que neste período os animais já atingiram maior peso vivo e as exigências de proteína metabolizável são diminuídas, dada a redução na quantidade de proteína no ganho, à medida que o animal aumenta de peso (SINDT et al., 1993; NRC, 1996), o que atenuaria a importância da degradabilidade da fração protéica das dietas nesta fase. Desta forma, a proteína de origem microbiana, tendo otimizado sua produção via fornecimento de fontes de PDR, aliada à fração de proteína dos alimentos que naturalmente escapa da degradação, seria suficiente para o atendimento das exigências protéicas dos animais.

Neste contexto, MILTON et al. (1997) também concluíram que fontes protéicas que escapam à degradação ruminal têm pequeno valor para animais jovens confinados alimentados com ração à base de milho moído, provavelmente porque as necessidades de proteína metabolizável seriam atingidas pela fração de proteína não degradável do milho e pela fração microbiana. Por este motivo, SINDT et al. (1993) estabeleceram que dietas para terminação de bezerros, à base de milho laminado, deveriam ser modificadas entre 40 e 80 dias de confinamento, passando de uma suplementação com fonte protéica de alto escape ruminal para a utilização de um suplemento de nitrogênio não protéico.

As médias dos parâmetros de carcaça são apresentadas na Tabela 4. Pela análise estatística não foi verificada diferença significativa $(\mathrm{P}>0,05)$ para peso vivo final, peso de carcaça quente, rendimento de carcaça, peso de traseiro, dianteiro e ponta de agulha. Da mesma forma, SHAIN et al. (1998) obtiveram resultados não significativos para o peso de carcaça quente de novilhos de ano castrados e confinados, alimentados com níveis crescentes de PDR, e MILTON et al. (1997) não observaram efeito de dietas contendo ou não fontes de PNDR sobre o peso e rendimento de carcaça quente de novilhos castrados e implantados.

Considerando os pesos de abate e os rendimentos de carcaça quente obtidos, os animais dos tratamentos T1, T2 e T3 pesaram, respectivamente, 16,02, 15,69 e 16,17@. Segundo Luchiari Filho (1992), citado por ARRIGONI (1995), o peso ideal de abate para as condições brasileiras, considerando-se os aspectos econômicos e de rendimento de cortes cárneos, está entre14 e16@.Portanto, verifica-se que os pesos de carcaça dos três tratamentos situaram-se dentro desta faixa adequada para comercialização.

As medidas de área de olho de lombo, gordura subcutânea e força de cisalhamento (Tabela 5), tomadas nas amostras de Longissimus dorsi, não diferiram entre os tratamentos $(\mathrm{P}>0,05)$. Estes resultados estão de acordo com COMERFORD et al. (1992), que não observaram respostas significativas para a espessura de gordura e área de olho de lombo de novilhos de ano cruzados recebendo farinha de 
Tabela 4 - Valores médios dos parâmetros de carcaça e seus respectivos desvios-padrão

Table 4 - Carcass traits mean values and its respectively standard deviations

\begin{tabular}{|c|c|c|c|c|}
\hline \multirow[b]{2}{*}{$\begin{array}{l}\text { Parâmetro } \\
\text { Trait }\end{array}$} & \multicolumn{3}{|c|}{$\begin{array}{c}\text { Tratamento } \\
\text { Treatment }\end{array}$} & \multirow[b]{2}{*}{$\mathrm{CV}(\%)$} \\
\hline & Т 1 & Т 2 & Т 3 & \\
\hline \multicolumn{5}{|c|}{$\mathrm{kg}$} \\
\hline $\begin{array}{l}\text { Peso vivo final } \\
\text { Final live weight }\end{array}$ & $435,8 \pm 41,8$ & $426,0 \pm 52,3$ & $434,9 \pm 41,5$ & 10,4 \\
\hline $\begin{array}{l}\text { Peso de carcaça quente } \\
\text { Hot carcass weight }\end{array}$ & $240,3 \pm 22,5$ & $\begin{array}{c}235,3 \pm 27,4 \\
\%\end{array}$ & $242,6 \pm 23,5$ & 3,1 \\
\hline $\begin{array}{l}\text { Rendimento de carcaça } \\
\text { Dressing percentage }\end{array}$ & $55,17 \pm 1,17$ & $\begin{array}{c}55,30 \pm 1,65 \\
\mathrm{~kg}\end{array}$ & $55,82 \pm 2,17$ & 10,1 \\
\hline $\begin{array}{l}\text { Peso de traseiro } \\
\text { Forequarter weight }\end{array}$ & $108,5 \pm 10,4$ & $107,1 \pm 10,1$ & $109,1 \pm 9,9$ & 9,5 \\
\hline $\begin{array}{l}\text { Peso de dianteiro } \\
\text { Hindquarter weight }\end{array}$ & $92,5 \pm 9,9$ & $90,6 \pm 12,5$ & $94,6 \pm 9,8$ & 11,6 \\
\hline $\begin{array}{l}\text { Peso de ponta de agulha } \\
\text { Plate }\end{array}$ & $34,9 \pm 4,1$ & $33,5 \pm 4,5$ & $34,6 \pm 4,3$ & 12,5 \\
\hline $\begin{array}{l}\text { T } 1-69 \% \text { PDR na Fase } 1 \text { e } 6 \\
\text { T } 2-77 \% \text { PDR na Fase } 1 \text { e } \\
\text { T } 3-61 \% \text { PDR na Fase } 1 \text { e } 6 \\
T 1-69 \% \text { DIP in Phase } 1 \text { and } 69 \\
T 2-77 \% \text { DIP in Phase } 1 \text { and } 69 \\
T 3-61 \% \text { DIP in Phase } 1 \text { and } 69\end{array}$ & $\begin{array}{l}\text { PDR na Fase } 2 . \\
\text { PDR na Fase } 2 . \\
\text { PDR na Fase } 2 . \\
\text { IP in Phase } 2 . \\
\text { IP in Phase } 2 . \\
\text { IP in Phase } 2 .\end{array}$ & & & \\
\hline
\end{tabular}

peixe ou farelo de soja. As espessuras de gordura de cobertura obtidas por McCOY et al. (1998) também não diferiram nas carcaças de bezerros castrados e confinados recebendo ou não fontes adicionais de PNDR em dietas contendo milho laminado a seco. Entretanto, MILTON et al. (1997) obtiveram maior espessura de gordura de cobertura e menor área de olho de lombo para os novilhos de ano castrados alimentados com dietas à base de uréia suplementadas com fontes de PNDR.

A maciez é tida pelos consumidores como o mais importante aspecto qualitativo da carne bovina (LUCHIARI FILHO, 1998). Portanto, é fundamental que os sistemas de produção tenham como meta à obtenção de carne macia. Assim, os valores da força de cisalhamento, verificados nas amostras do presente estudo, estão de acordo com FELÍCIO (1997) numa faixa aceitável de maciez, ou seja, abaixo de 5,0 kgf.

Com relação à gordura subcutânea ou de cobertura, esta vem se tornando um importante indicador de qualidade, pois pode afetar a velocidade de resfriamento da carcaça, comportando-se como um eficiente isolante térmico (FELÍCIO, 1997). Assim, é importante que carcaças com adequada cobertura de gordura sejam obtidas, visando reduzir os efeitos de desidratação e encurtamento ("cold shortening") resultantes do resfriamento, os quais, dentre outros, podem causar endurecimento da carne (PARDI, 1993). Neste sentido, a espessura de gordura subcutânea verificada nas carcaças (média em torno de $5,0 \mathrm{~mm}$ ) está de acordo com as exigências mínimas da indústria frigorífica e especificações do Programa Novilho Precoce do estado do Mato Grosso do Sul, que exige cobertura de gordura entre 3 e $10 \mathrm{~mm}$ (ALMEIDA, 1996).

$\mathrm{Na}$ Tabela 5 são apresentadas as médias da composição química das amostras de carne. Não se detectou diferença significativa para umidade, proteína bruta e extrato etéreo ( $P>0,05)$. MILLS et al. (1992), ao estudarem os efeitos do fornecimento de farelo de soja ou farinha de peixe sobre a composição da carne de novilhos de ano cruzados, não verificaram diferença significativa entre os tratamentos para a análise química do músculo Longissimus dorsi quanto à umidade, proteína e gordura.

A marmorização, como característica de melhor acabamento de bovinos, tem sido discutida. A sua presença em proporções visíveis a olho nu, ou seja, representando mais de $4 \%$ de extrato etéreo na matéria natural, proporciona mais sabor e suculência à carne. Porém, a 
Tabela 5 -Medidas do Longissimus dorsi e seus respectivos desvios-padrão

Table 5 - Longissimus dorsi measures and its respectively standard deviations

\begin{tabular}{|c|c|c|c|}
\hline \multirow[b]{2}{*}{$\begin{array}{l}\text { Parâmetro } \\
\text { Trait }\end{array}$} & \multicolumn{3}{|c|}{$\begin{array}{c}\text { Tratamento } \\
\text { Treatment }\end{array}$} \\
\hline & T 1 & $\mathrm{~T} 2$ & T 3 \\
\hline $\begin{array}{l}\text { Área de olho } \\
\text { de lombo } \\
\text { Rib eye area }\end{array}$ & $66,76 \pm 6,56$ & $\begin{array}{c}\mathrm{cm}^{2} \\
66,89 \pm 7,56\end{array}$ & $66,06 \pm 5,86$ \\
\hline $\begin{array}{l}\text { Gordura subcutânea } \\
\text { Subcutaneous fat }\end{array}$ & $4,9 \pm 1,7$ & $\begin{array}{c}\mathrm{mm}_{5,1 \pm 2,1} \\
\mathrm{kgf}\end{array}$ & $5,1 \pm 1,7$ \\
\hline $\begin{array}{l}\text { Força de } \\
\text { cisalhamento } \\
\text { Shear force }\end{array}$ & $3,9 \pm 0,72$ & $4,6 \pm 1,15$ & $4,5 \pm 1,29$ \\
\hline $\begin{array}{l}\text { Umidade } \\
\text { Water }\end{array}$ & $74,96 \pm 1,24$ & $75,18 \pm 1,35$ & $75,22 \pm 0,83$ \\
\hline $\begin{array}{l}\text { Proteína } \\
\text { Protein }\end{array}$ & $18,57 \pm 0,67$ & $18,29 \pm 0,72$ & $18,25 \pm 0,78$ \\
\hline $\begin{array}{l}\text { Extrato etéreo } \\
\text { Ether extract }\end{array}$ & $1,92 \pm 1,28$ & $1,89 \pm 0,74$ & $1,68 \pm 0,56$ \\
\hline
\end{tabular}

1 T 1 - 69\% PDR na Fase 1 e 69\% PDR na Fase 2.

T 2 - $77 \%$ PDR na Fase 1 e $69 \%$ PDR na Fase 2.

T 3 - 61\% PDR na Fase 1 e 69\% PDR na Fase 2.

T $1-69 \%$ DIP in Phase 1 and 69\% DIP in Phase 2.

T $2-77 \%$ DIP in Phase 1 and 69\% DIP in Phase 2.

T $3-61 \%$ DIP in Phase 1 and 69\% DIP in Phase 2.

tendência é que tais vantagens sejam trocadas pelo consumidor por um produto mais saudável; portanto, a carne desprovida de gordura visível será mais desejável (FELÍCIO, 1997). Dessa forma, verifica-se que o teor de extrato etéreo determinado nas amostras, em média $1,89 \%$, é indicativo da pequena quantidade de gordura de marmorização depositada na carne, que é característica do modelo biológico Superprecoce, pois, além do abate de animais não castrados, estes são jovens, com idade em torno de 12 meses, constituindo-se em produto mais adequado às novas exigências de mercado.

Na Tabela 6 são apresentadas as médias da área de olho de lombo e gordura subcutânea tomadas por ultra-sonografia, destacando a diferença significativa $(\mathrm{P}<0,05)$ entre o tratamento $\mathrm{T} 1 \mathrm{e} \mathrm{T} 3$ quanto à área de olho de lombo em relação ao menor valor observado nos animais do tratamento T2 na primeira avaliação. Em relação à segunda medida, pode-se observar que tal diferença não foi detectada, ficando próximos os valores dos três tratamentos.
Tabela 6 - Medidas tomadas por ultra-sonografia e seus respectivos desvios-padrão

Table 6 - Ultrasound measures and its respectively standard deviations

\begin{tabular}{lccc}
\hline & \multicolumn{3}{c}{$\begin{array}{c}\text { Tratamento } \\
\text { Treatment }\end{array}$} \\
\cline { 2 - 4 } $\begin{array}{l}\text { Parâmetro } \\
\text { Trait }\end{array}$ & T 1 & T 2 & T3 \\
\hline
\end{tabular}

Primeiramedida

First measure

Área de olho

$\mathrm{cm}^{2}$

de lombo

Rib eye area

Gordura subcutânea 3,8 $\pm 1,2$

Subcutaneousfat

Segunda medida

Second measure

Área de olho

$63,07 \pm 5,84$

$\mathrm{cm}^{2}$

de lombo

$61,48 \pm 7,46 \quad 61,10 \pm 6,48$

Rib eye area

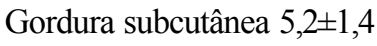

$\mathrm{mm}$

$4,5 \pm 1,6$

$5,3 \pm 1,9$

Subcutaneousfat

${ }^{1}$ T 1 - 69\% PDR na Fase 1 e 69\% PDR na Fase 2.

T 2 - 77\% PDR na Fase 1 e $69 \%$ PDR na Fase 2.

T $3-61 \%$ PDR na Fase 1 e 69\% PDR na Fase 2.

Médias seguidas de letras distintas nas linhas diferem entre si pelo teste de Tukey $(\mathrm{P}<0,05)$.

$T 1-69 \%$ DIP in Phase 1 and $69 \%$ DIP in Phase 2.

T $2-77 \%$ DIP in Phase 1 and 69\% DIP in Phase 2.

$T 3-61 \%$ DIP in Phase 1 and 69\% DIP in Phase 2.

Means followed by different letters in the row are different by Tukey test $(P<.05)$.

A utilização da ultra-sonografia como ferramenta de contribuição para o estudo do crescimento e avaliação da deposição de gordura subcutânea, mostrou-se adequada, pois permitiu visualizar a evolução comparativa entre os tratamentos quanto ao crescimento do músculo Longissimus dorsi, nas duas fases do experimento, o que não poderia ser avaliado por outro método prático, quer por ganho de peso quer por atribuição de escore muscular.

\section{Conclusões}

Durante a fase inicial de confinamento, há necessidade da utilização de dietas com menores níveis de PDR, tendo em vista o atendimento das elevadas exigências de proteína metabolizável neste período, devido ao rápido crescimento muscular dos animais. $\mathrm{Na}$ fase final, o nível de $69 \%$ de PDR, independentemente dos níveis de PDR da fase inicial, mostrou-se adequado para atingir as metas de desempenho e peso 
comercial de abate, propostos para bovinos superprecoces.

A característica de degradação protéica das dietas na fase de crescimento não interferiu nos parâmetros de carcaça e qualidade de carne estudados.

As carcaças avaliadas apresentaram valores de gordura subcutânea e pesos adequados para comercialização, além de carne com maciez desejável, o que caracteriza a possibilidade de utilização de animais jovens e não castrados para a produção de carne.

A utilização da ultra-sonografia contribuiu para melhor compreensão do crescimento do tecido muscular, possibilitando também identificar a quantidade de gordura subcutânea sobre o músculo Longissimus dorsi, permitindo utilizar este parâmetro para identificação do ponto de abate, de acordo com as exigências da indústria frigorífica.

\section{Referências Bibliográficas}

ASSOCIATION OF OFFICIAL ANALYTICAL CHEMISTS AOAC. 1985.Official methods of analysis. 13. ed. Washington, D.C. $1094 \mathrm{p}$.

ALMEIDA, A.J. 1996. O Novilho Precoce no Mato Grosso do Sul. Campo Grande: UFMS. 170p.

ARRIGONI, M.B. Efeito da restrição alimentar sobre o desempenho, área e tipos de fibras musculares em bovinos jovens confinados. Jaboticabal, SP: FCAV, 1995. 73p. Tese (Doutorado em Zootecnia) - Faculdade de Ciências Agrárias e Veterinárias/ UNESP, 1995.

COMERFORD, J.W., HOUSE, B., HARPSTER, H.W. et al. 1992. Effects of forage and protein source on feedlot performance and carcass traits of holstein and crossbreed beef steers. J. Anim. Sci., 70:1022-1031.

COOMER, J.C., AMOS, H.E., FROETSCHEL, M. et al. 1993. Effects of supplemental protein source on ruminal fermentation, protein degradation, and amino acid absorption in steers and on growth and feed efficiency in steers and heifers. J. Anim. Sci., 71:3078-3086.

FELÍCIO, P.E. Fatores ante e post mortem que influenciam na qualidade da carne bovina. In: PRODUÇÃO DO NOVILHO DE CORTE, 4, 1997, Piracicaba. Anais... Piracicaba: FEALQ, 1997. p.79-97.

FLUHARTY, F.L., LOERCH, S.C., SMITH, F.E. 1994. Effects of energy density and protein source on diet digestibility and performance of calves after arrival at the feedlot. J. Anim. Sci., 72:1616-1622.

KNAUS, W.F., BEERMANN, D.H., ROBINSON, T.F. et al. 1998. Effects of a dietary mixture of meat and bone meal, feather meal, blood meal, and fish meal on nitrogen utilization in finishing holstein steers. J. Anim. Sci., 76:1481-1487.

LANNA, D.P.D., FOX, D.G., TEDESCHI, L.O. Exigências nutricionais de gado de corte: o sistema NRC. In: SIMPÓSIO SOBRE PRODUÇÃO INTENSIVA DE GADO DE CORTE, 1998, Campinas. Anais...Campinas: CBNA, 1998. p.138-168.

LOERCH, S.C., BERGER, L.L., PLEGGE, S.D. et al. 1983. Digestibility and rumen escape of soybean meal, blood meal, meat and bone meal and dehydrated alfafa nitrogen. J. Anim. Sci., 57:1037-1047.
LUCHIARI FILHO, A. Perspectivas da bovinocultura de corte no Brasil. In: SIMPÓSIO SOBRE PRODUÇÃO INTENSIVA DE GADO DE CORTE, 1998, Campinas. Anais do Simpósio sobre Produção Intensiva de Gado de Corte. Campinas: CBNA, p.1-10, 1998.

McCOY, R.A., STOCK, R.A., KLOPFENSTEIN, T.J. et al. 1998. Effect of energy source and escape protein on receiving and finishing performance and health of calves. J. Anim. Sci., 76:1488-1498.

MILLS, E.W., COMERFORD, J.W., HOLLENDER, R. et al. 1992. Meat composition and palatability of holstein and beef steers as influenced by forage type and protein source. J. Anim. Sci., 70:2446-2451.

MILTON, C.T., BRANDT, JR., R.T., TITGEMEYER, E.C. et al. 1997. Effect of degradable and escape protein and roughage type on performance and carcass characteristics of finishing yearling steers. J. Anim. Sci., 75:2834-2840.

MÜLLER, L. 1987. Normas para avaliação de carcaças e concurso de carcaças de novilhos. 2.ed. Santa Maria: Imprensa Universitária. $31 \mathrm{p}$.

NATIONAL RESEARCH COUNCIL - NRC. 1996. Nutrient requirements of beef cattle. 7.ed., Washington D.C. 242p.

OWENS, F.N., ZINN, R.A., KIM, Y.K. 1986. Limits to starch digestion in the ruminant small intestine. J. Anim. Sci., 63:1634-1648.

PARDI, M.C. 1993. Ciência, Higiene e Tecnologia da Carne. Vol.1. Goiânia: EDUFF. 586p.

PERKINS, T.L., GREEN, R.D., HAMLIN, K.E. et al. 1992. Ultrasonic prediction of carcass merit in beef cattle: Evaluation of technician effects on ultrasonic estimates of carcass fat thickness and logissimus muscle area. J. Anim. Sci., 70:2758-2765.

PERRY,T.W., CECAVA, M.J. 1995. Beefcattlefeeding and nutrition. San Diego: Academic Press. 389p.

SAMPAIO, A.A.M., BRITO, R.M., VIEIRA, P.F., et al. 1997. Efeito da suplementação protéica sobre crescimento, terminação e viabilidade econômica de bezerros mestiços Canchim confinados pósdesmama. R. Bras. Zootec., 27:823-831.

SAS INSTITUTE INC. 1985. Sas User's Guide. 5. ed. Cary, NC. 956p.

SHAIN, D.H., STOCK, R.A., KLOPFENSTEIN, T.J., et al. 1998. Effect of degradable intake protein level on finishing cattle performance and ruminal metabolism. J. Anim. Sci., 76:242-248.

SINDT, M.H., STOCK, R., KLOPFENSTEIN, T.J., et al. 1993. Protein sources for finishing calves as affected by management system. J. Anim. Sci., 71:1047-1056.

TITGEMEYER, E.C., MERCHEN, N. R., BERGER, L. L. 1989. Evaluation of soybean meal, corn gluten meal, blood meal and fish meal as sources of nitrogen and amino acids disappearing from small intestine of steers. J. Anim. Sci., 67:262-275.

VALADARES FILHO, S.C. Eficiência de síntese de proteína microbiana, degradação ruminal e digestibilidade intestinal da proteína bruta, em bovinos. In: SIMPÓSIO INTERNACIONAL SOBRE EXIGÊNCIAS NUTRICIONAIS DE RUMINANTES, 1995, Viçosa. Anais ... Viçosa: UFV, 1995. p.355-388.

WHEELER, T.L., CUNDIFF, L.V., KOCH, R.M. 1994. Effect of marbling score degree on beef palatability in Bos taurus and Bos indicus cattle. J. Anim. Sci., 72:3145-3151.

ZINN, R.A., BULL, L.S., HEMKEN, R.W. 1981. Degradation of supplemental proteins in the rumen. J. Anim. Sci., 52:857-866.

ZINN, R.A., OWENS, F.N. 1993. Ruminal escape protein for lightweight feedlot calves. J. Anim. Sci., 71:1677-1687.
Recebido em: 24/08/00 Aceito em: 02/05/01 